\title{
THE POWER OF WORDS: LINGUISTIC PATTERNS IN ENGLISH, MAY THEY AFFECT OUR WORLD VIEW?
}

The issue about what comes first language or thought is a widely discussed one, and a good number of linguists, psychologists, and experts in different fields have researched and published about this dilemma. Can we think without language? Could thought be separated from the word? There are divergent opinions, but one that met wide consensus in the second half of the twentieth century was that languages do influence thought in one way or another. The Sapir \& Whorf hypothesis, known as the linguistic relativity principle, sustained that cultural concepts and categories in a given language affect its speakers' cognitive classification of the universe: according to this theory speakers of different languages would think and act differently due precisely to the influence received by means of conceptions acquired in their first language. Thus, when we learn to speak our native language, along with it, we are also acquiring categorizing methods that will serve us to establish taxonomies to understand the world (Sapir 1983).

Roger Brown and Lenneberg identified the two basic tenets of Whorf's thesis and summarised them as follows: "the world is differently experienced and conceived in different linguistic communities" (1954: 455); and "language causes a particular cognitive structure" (1954: 457). These principles were later developed by Brown into what has been called the "weak linguistic relativity", in which it is understood that language limits thought; and the "strong linguistic relativity" where language determines thought. Brown's idea that the structure of a given individual's first language strongly influences and even determines the worldview he will acquire as he learns the language flies in the face of other theories such as that of professors of Psychology Hespos and Spelke (2004) who did a number of experiments and showed that, contrary to what other scholars believed, children learn to think independently about objects before they learn language. In recent years some scholars working on linguistic relativity such as cognitive psychologist Lera Boroditsky have come to the conclusion that languages shape the way we think (2009), but in a more limited way that was previously believed. It is the boundaries between thought, language, and culture that should be examined to understand this interrelatedness. 
For the issue under discussion here what is of consequence is the fact that there is a quite extended idea among linguists that language influences thought, though it might be of great help to understand to which degree we are determined by the linguistic patterns we learn in our childhood and handle throughout our lives. It is these learned patterns that may contribute to numb or destroy our empathy for the living creatures around us. Without getting too deep into linguistic theories we can deduce that if language shapes our view of the world, it would be convenient to examine and control the language we are exposed to, for it may lead us to accept attitudes that are negative or damaging for ourselves and for our environment.

\section{Are the physical, the mental and the verbal related?}

Focusing on violence and aggression it should be clarified that these terms refer to behaviour aimed at causing some kind of harm, which can be exerted between members of the same species and between members of different species. In years gone by aggression was often identified with physical damage, as if it were the only possible source of pain: hence we may find proverbs such as, "sticks and stones break my bones but words can never hurt me". However, as societies have advanced there has been an obvious acknowledgment of other types of harm and violence: aggression may be physical, mental or verbal. As speakers of a given language, we should be aware of the remarkable effects that language may have on reality. Everyone seems to understand that violent or abusive acts produce physical consequences, but we tend to forget that abusive and violent speech can also produce effects and reactions: in a way, speech is a sort of action, and therefore can cause negative consequences as well. Word selection in a conversation can have a remarkable impact. For instance, many of us may be able to track back in our memories from infancy scenes in which something derogatory said about us hurt us deeply and has stayed in our memory ever since (name calling, for instance). We can all probably remember an insult meant to humiliate or degrade us in our school years, and we may even experience those feelings just by remembering the episode. Words are extremely powerful, and they may assist to shape thoughts that, by dint of repetition, we come to accept as universal truths. 
Proverbs, sayings, citations, and so forth are linguistic elements that contribute to the shaping of images about the world and the creatures that inhabit it, human or non-human. We here analyse some speech patterns that, we believe, strengthen negative concepts about non-human creatures, namely: they are not to be trusted, they are stupid, they are dirty and possess many other negative traits. In this scenario, if a human individual is accused of being dirty, this person may be said to be "a pig": this epithet which is, of course, intended as an insult, is based on pigs habits such as that of coating themselves in mud, and it ignores the fact that they do it to protect from the sun and the heat and to refresh their skin. This verbal negative image of pigs fails to notice the fact that females and males of our own species also cover their faces and bodies with all kinds of make-ups and beauty ointments, the contact with which is in all probability far more hazardous for our health than the sheer mixture of water and earth pigs use for their grooming, and no doubt for less futile reasons. And, speaking about porcines another saying comes to our mind: "you cannot make a silk purse out of a sow's ears". What seems to be the meaning here is that something isn't very good to start with; and that not much can be done to improve its value. It should be unacceptable to trivialize with the idea of using animal flesh and cartilage to make a purse, which by the way, could be more easily made from a variety of vegetable raw materials; in addition, the expression disdains the animal by implying that the reasons why a purse should not be made from it is by no means that such an action would require cutting off the animal's ear or even killing it, but that the result would not be worthwhile.

Likewise, when a human is said to "act like an ape" the expression conveys the idea that this person acts foolishly, and even wildly. This saying assumes that apes are foolish and wild. Again we neglect to recognize that there is no creature on our planet who can act more foolishly and wildly than man can. How else can we explain the fact that humans are capable of risking their health and even their life in many different ways out of sheer vanity? Let's just think for a moment about plastic surgery, for instance, to mention but one life risking procedure for which the motivation is in the vast majority of cases pure narcissism. There is a whole range of fashionable foolish human habits which, unlike those apes exhibit, are done in full consciousness of the negative aspects: for instance, researchers have long linked high heels and knee osteoarthritis, ankle sprains, and other problems, but a great majority of females still wear them for esthetic purposes. This seems a much more foolishly behavior than an ape's antics which are, after all, spontaneous expressions. On the other hand, when 
someone gets excessively angry he/she may be said "to go ape" applying another comparison which gives a negative picture of non-human animals. Another similar idiom, "monkey business" also reinforces the idea that monkey's behaviour is silly and mischievous, if not unethical and deceitful.

In a different quarter a man can "eat like a horse", a comparison which refers to someone eating too much: this once more ignores that it is humans who, in spite of their awareness that they will have enough to eat the following day, often stuff themselves to the point of endangering their health.

Many other examples of language which remind us of the violence we exert on animals are found in common expressions and proverbs: one of them is "to hit the bulls-eye". The most generalized meaning is to reach the main point of an issue: and to express it, the expression trivializes an act which is intrinsically wrong and contributes to the idea that violent acts towards animals do not even need to be justified.

With dogs, our most familiar companions, many inexcusable cruelties are committed daily which an abundance of sayings acknowledge openly. "To lead a dog's life" conveys the meaning of working hard and being treated in a callous manner, and it implies the general belief that dogs are treated badly with no consequences for the aggressor. In the same line, when somebody is said to be "in the doghouse", it is understood that he has fallen in public disgrace or disfavor. Being "a hound" may be understood as a positive quality if you have a profession which entails chasing or pursuing something or someone such as detective; but what most people mean when they call someone "a hound" is that the receiver of the epithet is "a contemptible person and a scoundrel"; "a dirty dog" is also a person who is deemed to be despicable or contemptible. Then, "to hound someone" has the connotation of pursuing someone relentlessly, with the determination of a hound (and with evil purposes in mind).

Then, of course, we have the widespread offence of calling someone an "ass" which has the overt connotation of being a pompous fool or a person who lacks good judgment; and "to make an ass of one self " again conveys the meaning of playing the fool and making a ridiculous figure of one self; these are reflected in the common expressions "don't be an ass!" and "what an ass I am!" Being called a "dumb bunny" is not flattering either, it is what people 
call themselves mentally or verbally when they are aware that they have done something incredibly stupid. "Donkey" is sometimes used in very much the same way as "as": it is applied to someone acting foolishly; also, "donkey work" is understood as hard and boring work, usually the hard part of a job for, as we know, donkeys were used to carry heavy loads. "To make a monkey out of someone" is equivalent to making somebody look stupid

One of the most popular and also most cruel proverbs is "to kill two birds with one stone", which denotes a situation in which we are aiming to, or have achieved, two objectives with a single effort. We obviously are not thinking of actually killing the two birds, but the image formed in our mind contributes to get familiar with the idea that killing birds is socially acceptable. It seems to me that if, as a friend of mine suggests we did, we instead used the expression "to save two birds with one stone" the idea that would adhere to our mind would instead be that of "saving" instead of that of "killing" the birds. One wonders if it would be equally accepted to say "to kill two ladies with one shot", certainly not since, fortunately, it is a long time now since women were officially considered second rate citizens in Western countries.

When someone is doing something pointless over and over, without arriving to any conclusion or profit, disapproval may be expressed by means of the common idiom "beating a dead horse", or alternatively "flogging a dead horse". This idiom seems to imply that what might be entirely acceptable is "beating a live horse, for, after all, it might yield the human performing the "beating" some kind of benefit; a possibility which is out of the question in the case of beating a dead horse. The image is certainly hideous for those of us who have any compassion and sense of justice for the fellow creatures with whom we share the planet; unfortunately, it passes quite unnoticed for the greater majority. What can be inferred from the idiom is that the usual procedure would be beating a horse while he is alive to make him yield to our desires, but certainly not a dead one. In the proverb "Trust not a horse's heel, nor a dog's tooth" popular wisdom warns that neither a horse nor a dog are faithful creatures whom you can trust but that in both cases their apparent meekness is misleading and you may be deceived.

Another "pearl of popular wisdom" seems to us the expression "it was the last straw that broke the camel's back" or the variant "it was the last stroke that broke the camel's back" for, 
figurative as they are, contribute to get the speakers used to the idea that a camel, just like a horse, a donkey or an ox can be overloaded or beaten as much as the "owners" wish. Curiously, the saying seems to recommend that the animal's tormentor should draw the line just before breaking the animal's back, possibly because the consequence of breaking it would entail a loss for the human doing the loading or the beating, with the obvious result of "killing the golden goose". So it seems that cruel actions against animals are only the target of criticism when they result in some loss for humans.

Talking about poultry and the idiom mentioned above, a hen or a goose that lays golden eggs is a magic creature that can be tracked back to Aesop's fable of the goose that laid golden eggs and even further back to Egyptian history. In more recent times we find the character in fairy tales such as that of the Brothers Grimm, "The Golden Goose". From those and other old stories and legends comes the modern idiom "Kill the goose that lays the golden egg". The idiom expresses the idea of destroying unnecessarily something that is profitable. It may be argued again that nobody has in mind killing a hen or a goose for the shake of benefiting from their golden eggs, but we constantly kill hens and geese and other animals for our benefit, so the proverb is too near the truth to be amusing. Again it reinforces the idea that killing a hen/ goose is an act which does not imply unacceptable violence. By dint of repetition we have come to accept the idea that killing animals has no evil consequences and should produce no remorse while it may not be so tolerable to say "to kill the footballer with the golden kick" or something of the kind. Another idiom related to poultry is used when we accuse someone of being a coward is to call this person "a chicken". It is used as an insult, however, it should not come as a surprise if we scare chickens, since all they can expect from us is imprisonment and death: we inspire justified fear in them, and then we say they are cowardly. As in the case of other animals, humans show total indifference for the destiny of poultry animals and this indifference is again supported by and reflected in verbal abuse.

The idiom "to smell a rat" is used to convey suspicion that something is amiss: the speaker senses that someone has acted wrong. For instance, a woman could express her distrust of her husband by telling a friend that she "smells a rat"; and a business man could use the same idiom to express his suspicion that a partner is playing a dirty trick on him. In the same key, to "rat out" someone means to betray this person, thus one may hear "the policeman ratted out his partner, and now the whole department has turned their back on him in revenge". The popular expression "rat race" is understood as a way of acting which involves rushing around 
in a confused way and seemingly without a purpose, and it then took the specific meaning of a fierce struggle for success, especially in one's career or business. All in all rats provoke either scorn or indifference in humans so the expression "give a rat's ass" expresses absence of care for a person or for the outcome of a situation: "I don't give a rat's ass about my ex-wife". We could continue quoting many other sayings of the kind, of which we include a selection.

Somebody considered very ugly is said to be "as ugly as a toad".

"To bug someone" is to annoy or irritate this person.

"A cold fish" is someone who is unfriendly with others.

"To have crocodile tears" is to show false sorrow and pretend to be crying.

"To be fishy" is to be suspicious or doubtful.

“A flea in someone's ear is an unwelcome idea or answer to a question.

"A fly in the ointment" is something of small size which spoils the fun.

"Louse up" is to spoil something or to make a mess with what you are doing.

"Open a can of worms" is to complicate things unnecessarily.

"A shark" is a person you cannot trust, ruthless and dishonest.

"A snake in the grass" is a deceitful or treacherous person.

"A snake oil salesman", a man who is trying to sell you something that does not work.

"A fine kettle of fish" is considered to be an unsatisfactory situation.

It may be argued that after all the words we use to refer to animals have little to do with the suffering we inflict on them; but disparaging expressions, vocabulary, proverbs and sayings no doubt numb our sense of justice and help us to take for granted that animals are good for nothing except to be sacrificed to our service. This negative image of animals helps to justify our abuse, making us believe that there is absolutely nothing wrong with using their fur, their flesh or their work for our benefit and pleasure. It is time we realize, in Alice Walker's words, that "The animals of the world exist for their own reasons. They were not made for humans any more than black people were made for white, or women created for men.”

So, all in all, we believe that a great number of idioms, proverbs, and sayings in the English language perpetuate negative images and ideas of animals, and that these images justify speciesism which is the widespread discrimination practiced by the great majority of human beings against other species. These attitudes are destroying not only millions of our fellow creatures but also, as Gary Lawrence Francione has observed, our very spirit. I would suggest 
that we practice a reversal of many of these common sayings and that we stop using those which abuse animals verbally or denote violent treatment of them. For instance, instead of the idiom "dead as a mutton" that surely reflects the doomed destiny of all lambs and sheep we should say "live as a lamb" and then act upon the saying by renouncing to eat the flesh of animals.

\section{REFERENCES}

Sapir, Edward (1983) David G. Mandelbaum, ed., Selected Writings of Edward Sapir in Language, Culture, and Personality, University of California Press.

Sapir, Edward (2002) The psychology of culture : a course of lectures. Ed. Judith T. Irvine Berlin: Mouton de Gruyter.

Brown, R and Eric Lenneberg (1954), "A study in language and cognition", Journal of Abnormal and Social Psychology 49: 454-46.

Hespos, S. J. and Spelke, E.S. (2004). "Conceptual precursors to language." Conceptual precursors to language. Nature, 430, 453-456.

Boroditsky, L. (2009). How does our language shape the way we think? In Brockman (Ed.) What's Next? Dispatches on the Future of Science. Vintage Press.

Robert Abraham Sullivan

University of La Rioja 